University of Washington Tacoma

UW Tacoma Digital Commons

$12-1-2018$

\title{
Creating Emancipatory Dialogues About Identity and Health by Modernizing Interviews
}

Doris M. Boutain

University of Washington

Robin Evans-Agnew

University of Washington Tacoma, robagnew@u.washington.edu

Fuqin Liu

Texas Woman's University

Marie-Anne S. Rosemberg

University of Michigan

Follow this and additional works at: https://digitalcommons.tacoma.uw.edu/nursing_pub

Part of the Nursing Commons

\section{Recommended Citation}

Boutain, Doris M.; Evans-Agnew, Robin; Liu, Fuqin; and Rosemberg, Marie-Anne S., "Creating Emancipatory Dialogues About Identity and Health by Modernizing Interviews" (2018). Nursing \& Healthcare Leadership Publications. 164.

https://digitalcommons.tacoma.uw.edu/nursing_pub/164

This Article is brought to you for free and open access by the Nursing \& Healthcare Leadership at UW Tacoma Digital Commons. It has been accepted for inclusion in Nursing \& Healthcare Leadership Publications by an authorized administrator of UW Tacoma Digital Commons. 


\section{Creating Emancipatory Dialogues}

\section{Creating Emancipatory Dialogues about Identity, Research, and Health by Modernizing Interviews}

\section{Doris M. Boutain, PhD, RN, PHNA-BC; \\ Robin Evans-Agnew, PhD, RN; \\ Fuqin Liu, PhD, RN; \\ Marie-Anne S. Rosemberg, PhD, RN}

Author Affiliations:

Psychosocial and Community Health, University of Washington School of Nursing, Seattle (Dr Boutain);

Nursing and Healthcare Leadership, UW Tacoma, Washington

(Dr Evans-Agnew);

College of Nursing, Texas Woman's University, Denton (Dr Liu); and

Department of Systems, Populations and Leadership, School of Nursing, University of Michigan, Ann Arbor (Dr Rosemberg).

Joseph Fletcher III is appreciated for support of this article.

The authors have disclosed that they have no significant relationships with, or financial interest in, any commercial companies pertaining to this article.

Researchers are questioning "the constrained and hegemonic use of demographic information in nursing research" 1 ( p 242$)^{2}$ as interviewees overtly challenge the use of static demographic classification systems. ${ }^{2}$ Thus, interviewees are forecasting a need to modernize knowledge development about their identity and health in inquiry. Qualitative researchers, however, rarely use interviews to explicitly elicit, discuss, or record interviewees' point of view of their demographic identity, and scholars using quantitative methods do not assume that need. Innovative interviews can elicit, explore, and report how research participants view their health as created in the context of their identity across time, place, and life stages.

Researchers can elicit insights about identity and health which are emancipatory and supportive of a social justice agenda. Research interviews can be designed to explore how 


\section{Creating Emancipatory Dialogues}

identity privileging and marginalizing informs health. This emancipatory focus could broaden what research participants describe as affecting their health related to their identities, and vice versa. However, demographic data is currently re-codified, collected, reified, and communicated as labels with implicit meaning, not as socially constructed categories of meaning. Deeper analysis of demographic data as identity-in-context data would spur researchers to understand participants holistically, and perhaps, encourage future research questions.

Although research approaches have changed over time, interviews as the most common data gathering strategy in qualitative research has not. Demographic data is frequently collected and reported as sample, descriptive data similar to specimen collection. Complex insights about how health is created, maintained, or altered as a result of one's self or perceived identity remains hidden using current interview techniques.

The purpose of this article is to document how the Identity, Research and Health Dialogic Open-Ended (I-ReH-DO) Interview was used across three separate research topics to develop emancipatory knowledge. An overview of the I-ReH-DO Interview as a transformative social justice direction for research is first provided. Secondly, the use of the I-ReH-DO Interview is described across three health issues relevant to populations worldwide, including asthma, hypertension, and preconception care. Implications of using the I-ReH-DO Interview are finally described. This article equips researchers with another way to strategically employ interviews to facilitate participants' discussions of their identity and health, using their own reference points.

\section{Demographics with a Focus on Peoplehood, Social Identity and Justice}

Demographic is from the Greek word demos, which means 'the people', and graphy indicating 'writing, drawing, or graphic representation'. 3 To render demographics is to focus on depicting people in such a way as to document peoplehood identity. Peoplehood is an 


\section{Creating Emancipatory Dialogues}

exploration of what makes humans united and separated in their experiences of the world, and understandings of each other. While identity is a complex concept which can be approached from the disciplines of sociology, psychology, philosophy, and anthropology ${ }^{4}$, this complexity is not often considered when gathering or reporting identity representation in nursing research. Determining who and how to render peoplehood identity - to historically connect personal identities within the larger social narrative of human life - is powerful and contributes to how we as researchers develop knowledge, question assumptions, and explore social justice issues. Research about social identity has the ability to normalize and disturb the basis of social understandings ${ }^{4}$ as well as understandings about health.

In light of social justice, peoplehood is viewed as socially and politically rendered in time such that diverse groups share equitable burdens and benefits. Social justice assumes no implicit social order such that divestments are made in some and investments are made in others based on peoplehood affiliations. ${ }^{5}$ A social justice agenda inspires researchers to understand social justice promotion or how conditions of peoplehood are related to equitable conditions for health. Researchers can also focus this agenda on social injustice by viewing peoplehood related to inequitable conditions for health, conditions which render unequal burdens and benefits. ${ }^{5}$

Research assumptions about what influences conditions of peoplehood and health must be questioned, especially when equities are persistently noted as a social injustice. A main hindrance for social justice advancement is assuming a privileged knowledge position about the life of others and implicitly rending social identity as a fixed condition of individual autonomy, not as a dynamic concept. When privilege is assumed and hidden, it can portrays one's own privilege as unrelated to the disentitlement and subsequent power-over and vulnerability of others. ${ }^{5}$ Researcher's elicitation of demographic information, which is identity in context data, 


\section{Creating Emancipatory Dialogues}

can move beyond assumptive categorizations of people to develop knowledge about diverse health experiences. It can open opportunity for new knowledge as well as the re-negotiation of power relationships between researchers and participants.

\section{The Identity, Research and Health Dialogic Open-Ended (I-ReH-DO) Interview as an Emancipatory Inquiry Direction}

The Identity, Research, and Health Dialogic Open-Ended (I-ReH-DO) Interview was created in the year 1999 and detailed design templates and processes for using the I-ReH-DO interview are reported elsewhere. ${ }^{2}$ This article documents new insights about how the I-ReH-DO Interview promoted emancipatory knowledge development across several research methodologies. In brief, the I-ReH-DO Interview explicitly acknowledges that identity, such as citizenship, caste, sexual, gender, racial, class, immigration and other identities, are dynamic social constructs which inform and influence health. Instead of asking participants to assign themselves to a predetermined identity classification, participants are invited to refer to themselves, and describe how those referenced identities are associated with particular health issues. Although researchers do analyze the social location of participants during or after interviews, ${ }^{6}$ the I-ReH-DO Interview provides an intentional, systematic method for co-creating data with interviewees. Interviewees label and describe themselves during interview interactions, share how identity informs their health in the interview, and provide data to be analyzed by researchers thereafter. The I-ReH-Do Interview builds upon the intersectional work advanced in critical nursing inquiry ${ }^{6}$ and also recognizes that the use an inter-sectional analysis after interviewing may not involve inviting participants to both label and ascribe meaning to their own identities as the I-ReH-DO Interview does. $^{2}$ 


\section{Creating Emancipatory Dialogues}

In summary, there are three main I-ReH-DO Interview process steps. ${ }^{2}$ First, researchers complete a worksheet to critically reflect upon the research purpose and aims, and the demographic peoplehood concerns relevant to the research. Secondly, researchers map and critique existing research surveys about identity, and create open-ended questions about identity and the research topic. These open-ended questions permit interviewees to define their identity, and how their identity informs their health concerns. For example, there may be one summary open-ended question asking interviewees which identities are most salient for health management. Sample summary questions are: "Which of these last questions matters most to you as someone who has to manage __ (the disease/health condition)?", "What part of your personal background means the most to you as a childcare provider for this childcare (circle one)?", and "What matters the most to you in terms of keeping our air clean?" Please explain.

The third process step in using the I-ReH-DO Interview happens after data collection. The researcher is engaged in a critical reflection of what was learned and how that learning challenged and confirmed their initial understandings. Researchers write which of their assumptions about identity were dismantled and reinforced. This is done from multiple, partial points of view, including the points of view of existing research, of the research participant, of the researcher, and of the social context in which the interview was conducted. Using the I-ReHDO Interview helps explicitly clarify "why certain demographic data are needed and how to ask those questions to inform knowledge development". ${ }^{2(p 130)}$

\section{Emancipatory Research Praxis: Case Exemplars}

In the next section, we showcase three cases to outline the inquiry benefits and challenges of using the I-ReH-DO Interview. There is particular emphasis on how inquiry is supportive of a transformative social justice agenda. Transformation in research involves a deliberate redesign of 


\section{Creating Emancipatory Dialogues}

the taken-for-granted inquiry approaches, a critical consciousness of power-relations, and a reconstruction of ways to gain data and analytic insights supportive of new knowledge. Interviewers were researchers oriented in the I-ReH-DO Interview and from different identity backgrounds from each other and from the participants. This allowed us to reflect upon our identity as well as the interviewee's identity both separately and with each other. We present our research and reflective inquiry across a range of emancipatory methodologies. Two cases used critical discourse analysis to guide the use of the I-ReH-Do Interview, while one case used critical ethnography as the research methodology. For each case we will first describe the research study, what participants shared as important related to their identity and health, and how the research interview reflectivity changed the researcher. Each researcher also reports about what could have been done differently.

Case 1: The Study Topic of Asthma Management

Why was this approach important for the research topic? Demographic variations in the management of asthma are long-standing in the United States with a particular emphasis on children and youth. Race, income, gender, and ethnic disparities, for example, persistently exist in hospitalization rates and have not been well-understood. ${ }^{7}$ Identity is often explored in asthma management studies as a demographic variable without a contextual, interpretative focus. This has a historical legacy related to identity, specifically racial identity, as equated with genes, which is contrary to the contemporary understandings that racial identity is a social construct. ${ }^{8}$

How was the approach used? The I-ReH-DO Interview was used to gain a deeper understanding of the social and health conditions that research participants related to asthma management. Critical discourse analysis was the methodology used in all research studies. The use of the I-ReH-DO Interview began after completing the consent form and asking interviewees 


\section{Creating Emancipatory Dialogues}

the first question, "Why did you decide to participant in this research study?". This approach has been used in five asthma management studies since 2011, including with daycare providers, ${ }^{9}$ youth, ${ }^{10,11}$ parents, ${ }^{12}$ and policy makers. ${ }^{13}$ After asking interviewees about how they describe themselves related to their gender, language, racial identity, and background, the interviewer says, "In summary, you said you were , and (using the words of the interviewer).

Of all of these last questions, which matter to you most as you manage asthma?" .

What knowledge insights were gained using the approach? The novel results varied in each study. When researching policymakers, they defined themselves mostly by their experiences $(n=8)$ or professions $(n=2)$. Policy makers privileged their professional experiences without sharing information about their social privilege or position. Nor did they link social power and privilege to asthma management disparities, unlike published reports on the topic. ${ }^{13}$ Thus, there appeared to be a professional dissonance with the idea that the social determinants of health informed asthma management disparities. This created a paradox between their professional and personal identities. The policy makers were there to accomplish a task - in this case to discuss "asthma management disparities" - in order to develop a statewide asthma plan. However, they did not speak of how power and privilege influenced the issue. ${ }^{10}$

In the same study, ${ }^{13}$ adolescents $(\mathrm{N}=20)$ described how their zip code $(n=4)$, the number of people with whom they lived $(n=8)$, their length of residence $(n=4)$, or the "worksituation" of their parents or guardians $(n=4)$ were important for asthma management. The number of people in residence was important to adolescents as they spoke about struggling to maintain an adequate diet and proper allergen control in dwellings. Adolescents shared how their guardians' work situations and their zip code influenced their ability to access resources. For instance, one teen described how she visited a school in a wealthy zip code where "they have a 


\section{Creating Emancipatory Dialogues}

sushi bar”. Urban mobility and gentrification, for example, impacted the teens. Teens went to school in areas where their parents could no longer afford to live or work. Parents moved to other areas which resulted in teens traveling longer from home to school. The increase in everyday travel time limited teens' time for adequate asthma self-management.

In a study of new immigrant Mexican women $(\mathrm{N}=11)$, women identified education $(n=$ $8)$, ethnicity $(n=5)$, age $(n=4)$, birthplace $(n=4)$, gender $(n=3)$ and preferred language $(n=2)$ as being important factors in managing their child's asthma. ${ }^{12}$ Mothers viewed their education as influencing their ability to manage asthma triggers and to communicate with healthcare providers and landlords. Operating in a new language influenced their facility to support their children's asthma management as well; yet, mothers spoke about their education primarily. They also shared how their birthplace was an important parenting influence compared to how they are able to parent in the US. Mothers, for example, described the different ways people of Mexican descent ventilated their homes in a hotter climate, and how the restrictions on choices of cleaning products limited exposures to asthma triggers in places where they grew up.

In these case examples, the I-ReH-DO Interview engaged participants in reflexive thinking about their identity and the relationship between their identity and motivation for research participation. The questions opened opportunity for participants to express who they are, rather than fit into societally conditional expressions about demographics. For example, the questions "How do you describe your gender?" and "How to you describe your racial identity?" opened interpretative spaces for identity expression and exploration. Particularly for youth, they identified as a student using terms about their grade and place in school. The youth did not fully identify themselves by normative demographic age ranges. This helped the researcher to see the relative importance of school-related identity as opposed to age in asthma management. 


\section{Creating Emancipatory Dialogues}

What were the challenges with the interview approach? The I-ReH-DO Interview contained the hardest questions to ask in the study. This is because the interviewees and interviewer were not accustomed to dialoguing about participant's identity. That is, research participants were not familiar with being asked about their identity in an open-ended way, and how their identity relates to their health. When completing the I-ReH-DO Interview with those in positions of power, there may be a disinclination to challenge assumptions of those in power such as was experienced by this researcher. At the same time, the open-ended questions allowed for identity exploration, and thereby the formation of a different type of interview rapport.

Institutional Review Boards (IRB) may not necessarily be concerned with identifying or adjudicating subtle transformations in power relations in the interview, or the data thus obtained. The risks involved with the I-ReH-DO Interview might be a heightened sense of vulnerability on the part of the participant concerning their identity. The interviewer may listen to information about identity for which he or she may not have the skills to respond. Further, IRB may not be prepared to appraise the risks of collecting identity data in this new way.

When the I-ReH-DO Interview is used after the signing of the consent form, there is a power shift. Interviewees describe the most important identities that affect their health, activating self-reflection in both the interviewer and interviewee. Interviewers may feel uncomfortable in the moment as they focus on actively engaging the interviewee by repeating and summarizing what the interviewee is saying as their identity. This creates moments of reflection and wonder which may be stressful for interviewers who prefer prescribed responses for which they are prepared.

What would you do differently? More time is needed to reflect upon the interview responses to gain understanding. Training in mindful listening ${ }^{14}$ techniques, that is, being self- 


\section{Creating Emancipatory Dialogues}

aware and other-focused inside the interview process, might enhance depth as the interviewer becomes more attentive to the range of identity expressions. For example, when several youth were recruited all at the same time from an after-school program, researchers were less able to discern opportunities for reflexive dialogue in a group setting. It was more difficult to follow the conversation as youth presented numerous new identity and health concepts.

\section{Case 2: The Study Topic of Hypertension Management}

Why was this approach important for the research topic? Hypertension self-management continues to be a challenge for affected individuals, family members, and their health care providers. ${ }^{15,16}$ Despite several existing interventions for hypertension management, it remains a persistent health disparity. Particularly, hypertension continues to garner attention in disconcerting reports of poor self-management and the resulting detrimental outcomes such as cardiovascular diseases, stroke, and even death. ${ }^{17}$

Such health challenges tend to be heightened when dealing with immigrant populations. The complexity of the socio-ecological context of the immigrants' lives in the US increase their risks for hypertension development ${ }^{18,19}$ and when coupled with their cultural principles often hinder holistic and effective self-management approaches. ${ }^{20,21}$ We do know that social constructs such as age, gender, race, and immigration status, and the intersectionality of these, affect health. ${ }^{22}$ However such consideration is poorly operationalized in hypertension research. A survey research study, for example, may report the association between age and a particular health outcome such as blood pressure levels. However these studies often do not account for the participants' perspectives on the relative importance of these identities for optimal blood pressure management. The I-ReH-DO Interview in this study of hypertension management in Haitian hotel housekeepers was employed to better understand the what, why, and how of 


\section{Creating Emancipatory Dialogues}

hypertension self-management from the participants' point of view. Key questions included: What about age, being a women, and being foreign born influenced the individual's' ability to manage their hypertension? What about being a black immigrant from Haiti affected their ability to manage their hypertension?

How was the approach used? After obtaining participants' consent, the primary investigator began the interviews guided by critical ethnography. Critical ethnography fosters self-reflectivity and empowerment by encouraging exploration of knowledge anchored within the context of past and current experiences, cultural interactions, and socio-political influences. Thus exploration of hypertension management with this critical ethnography allowed not only for the consideration of cultural practices but also how social processes (social-political influences) impact knowledge and behavior (in this case, toward disease management). For example, after a participant responded that she considered herself a woman, the principle investigator proceeded with the demographic identity specific follow-up question "How do you think being a woman influences how you manage your hypertension?" The same inquiry approach continued with all identity concepts identified as relevant to the study and participant, including age, marital status, number of people in the household, kinship, education, income, length of stay in the US, and whether they maintain contact with friends and family in their home country. Participants reflected on how their cultural experiences and hegemonic constructs (e.g. gender) affected their knowledge and management of hypertension. As guided by critical ethnography, participants were the expert in their own knowledge and experiences. During analysis the researcher considered these social-cultural, economic and political contexts that were brought forth. The emancipatory research goal emphasized participants' voices and experiences, and the sociopolitical processes that can be eradicated through consciousness raising and policy change. 


\section{Creating Emancipatory Dialogues}

What knowledge insights were gained using the approach? This was a study about hypertension management with women $(\mathrm{N}=27)$ and men $(\mathrm{N}=4)$ who were Haitian immigrants working as hotel cleaners. ${ }^{22}$ The I-ReH-DO Interview allowed participants to critically reflect upon and speak about their worldview in relation to hypertension. Participants discussed the importance and challenges of managing hypertension while maintaining transnational relationships. They also voiced how these relationships presented a duality of social support and financial burden associated with sending remittance. For example, when asked how do they believe sending \$_ (the amount spoken was what the interviewee said was given in US dollars) to family members affected their ability to manage their hypertension, they noted that although they take joy in this action of sending remittance (e.g., money) to care for their loved ones, it also was a financial strain. It often prevented them from purchasing their blood pressure medication or paying their copay to doctor visits. ${ }^{23}$ Thus, by using I-ReH-DO Interview, the researcher identified transnational identity as an important hypertension management concern.

The I-ReH-DO Interview is an innovative way to position participants' voice over hegemonic framings of healthcare behavior, such as compliance to medication regiments. Knowing the participant's identity and health concerns enabled deeper reflection for the researcher during subsequent data collection and analysis. ${ }^{23}$ Appraising identity constructs in terms of how health is enacted or constrained gave the researcher an enlarged view of the Haitian participants' ability to care for themselves.

What were the challenges with the new interview approach? Challenges noted with the IReH-DO Interview by this researcher were the extra time required to conduct the interviews, and analyze and present the data in publications. Unlike standard demographic questionnaires which mostly only include multiple choice questions, with the I-ReH-DO Interview, the researcher and 


\section{Creating Emancipatory Dialogues}

participants needed extra time for the follow-up inquiry. In reports, it required more time to innovate ways to synthesize and present this data to make it palatable and applicable for interventions and policy adaptation. Statistical listing of 'demographic variables' as the normative standard in research reports, for example, could not be easily done.

What would you do differently? One possible helpful approach could have included providing insights the researcher gained in publications. During data collection many participants were surprised by the follow up questions because they were accustomed to just checking 'the box' (e.g. for age, gender, income). This was the first time that they were asked to think about and specifically share how being a transmigrant, a woman, and so forth affected their ability to manage hypertension. This type of questioning about identity and health as social constructs initiated some deep self-reflection on the part of the researcher and it could be shared more in publications to help others design future research studies.

\section{Case 3: The Study Topic of Preconception Care}

Why was this approach important for the research topic? Preconception care related research is heavily focused on risk management, thus confined within the biomedicine oriented risk reduction framework. As a result, demographic data across preconception care research are treated as label-based terminology. While women of reproductive age are at the center of the current preconception care conceptual model, ${ }^{24}$ their views on their identity and how they think their identity is related to their health before pregnancy (known as preconception health) have not been acknowledged. The most commonly referenced definition of preconception care by the U.S. Centers for Disease Control and Prevention (CDC) Select Panel identifies three categories of risks as central to preconception health, and these risks are biomedical, behavioral, and social risks. ${ }^{25}$ These categories, in turn, influence the habitual practice of researchers' designing 


\section{Creating Emancipatory Dialogues}

demographic questionnaires as discrete and static variables. Demographic information is often treated as fixed and neutral data classifications even in qualitative, and social-justice oriented, preconception care research. $^{26}$ The I-ReH-Do Interview was used with the goal of socially constructing identity and preconception care with three groups of stakeholders in rural China.

How was the approach used? Throughout the preconception care study, the researcher maintained constant reflection on the issues of the power sharing and imbalances. The researcher acknowledged the power imbalances in research practice between the researcher and the participant and also in utilizing interview questioning strategies central to knowledge cocreation. Naming and defining are important aspects of socially constructing identity. The naming of the study participants was carefully done during the study design.

The researcher consulted with key informants and employed uncommonly used terms to name two groups of study participants, and these were "adult daughters," and "maternal mothers." Adult daughter was a term used in the study to differentiate the population of adult reproductive-age women from other groups, such as teenagers. Maternal mother in the study was also a socially constructed term to specify their relationship with adult daughters.

Similar to exemplar two, women were asked to discuss their various demographic identities in relation to the research topic. The I-ReH-DO Interview contained discrete questions accompanied with open-ended questions. For example, the adult daughter's demographic form listed "What is your birth date?" as the first question. The question was accompanied with the following open-ended question "How does age affect having a healthy first baby? How so? How not?" These open-ended questions allowed participants to provide their views on whether age is related to preconception health and care. Researchers may think it is, but participants' views may 


\section{Creating Emancipatory Dialogues}

differ. The open-ended questions were non-judgmental, giving research participants opportunities to explore identity in relation to preconception care.

What knowledge insights were gained using the approach? The I-ReH-DO Interview supported emancipatory thinking on the part of the researcher. It was hard to view the demographic data as sample characteristic data, but instead data was thought of within the deeper socio-ecological context of the participant's experience. There were a total of sixteen questions in the adult daughter's I-ReH-DO Interview, ranging from age, to education, to income, to risk behaviors such as smoking, drinking, etc. Participants explained each question and demographic identity issue (described as "risk factor" in other studies) from their perspective. These risk factors became no longer mere labels of a person, rather they became a part of the story of personhood and personal context in relation to preconception health and care.

Interviewees also expressed their views on government preconception policy and preconception care. Interviewees, for example, shared that the well-intended preconception care government policies were not fully valued by rural, childbearing women. Interviewees viewed policies as a formality, not connected to their rural reality. While the Chinese government focused on the provision of free preconception care services, the women were more concerned about the care quality than access.

\section{What were the challenges with the interview approach? The I-ReH-DO Interview} differed from the conventional interview about demographic information. It challenged the researcher to reflect first on which identity and health questions were most relevant to ask. It elicited data in a new way, encouraging both the interviewer and interviewee to question who had interpretative authority in the research analysis. For example, relating the demographic information to the reason that makes it important for research helps detangle the normative 


\section{Creating Emancipatory Dialogues}

tendency of labeling. ${ }^{2}$ It also held the researcher accountable to report what the research participants valued related to their identity and health, and not add interpretative judgements 'speaking for' the participants which might be contrary to the participant's views.

What would you do differently? At the time of designing the research, resources and references about how to conduct research differently given the social construction of identity and health were scarce. The researcher struggled with designing the open-ended identity questions. Unlike example one, where the researcher asked interviewees why they choose to participate in the study, the researcher in this study did not. If the why participating question was asked, it could have elicited richer information about the participants' self-positioning in the social contexts.

Furthermore, the integration of the I-ReH-DO Interview finding along with the other data was not deep enough. There was limited time used to integrate the data into the reflective study analysis. Thus, the third step of the I-ReH-Do Interview, which happens after the data collection, was not as comprehensive.

\section{Discussion}

Identity and health labeling is a commonplace method in nursing research that is often mentioned yet not intentionally described. The labeling is often unquestioned by researchers in inquiry until interviewees ask why certain information is asked while other information is unsolicited. ${ }^{1}$ The normalization of the ritual of identity data gathering as similar to specimen collection extends into the collective memory of future researchers and publication readers, and limits transformative knowledge advancement.

One purpose of the Identity, Research, and Health Dialogic (I-ReH-DO) Interview is to intentionally explore identity related to the specific research purpose and topic. The participatory 


\section{Creating Emancipatory Dialogues}

interviewing and meaning making processes interrupts the normative script of identity classification by researchers and participants. The I-ReH-DO Interview makes visible the invisible assumptions about what is important about identity and health. In the case of the asthma studies, there was a purpose question at the start of the interview of "Why do you want to be in this study?". This question illuminated reasons which compelled participants into the research encounter. The purpose question also links to the I-ReH-DO Interview. The introduction question is used to let the participants know that their thoughts matter in the research.

The I-ReH-DO Interview is helpful to researchers who want to engage in emancipatory inquiry. We engaged in the process of re-thinking both why and how to elicit, analyze, and document identity and health data. The I-ReH-DO Interview prompted reflective and analytic questions such as: 1 . Which questions do researchers need to ask about identity related to this particular research topic? Why so? Why not?, 2. How do we as researchers ask about identity data that is irrelevant to the particular research topic? What are the intentional or unintentional outcomes?, 3. Were the participants given a choice to determine which demographic identity data was important to them related to their health? What are the intentional and unintentional outcomes? and 4. What surprised you as a researcher about the participant's understanding of their identity, and what does this say about the researcher's perceptions of power relations in society and in research? These questions helped us as researchers develop a more nuanced reflection of our work, and examine systems of demographic codification for their implicit power implications and limitations. Thus, using the I-ReH-DO Interview advanced our intentions for explicit critical reflection and emancipatory knowledge development.

We learned that identity matters to participants in ways that we had not known. This enabled us to question the existing research or re-search our understandings. For example, how is 


\section{Creating Emancipatory Dialogues}

the participant's selected identity noted in the existing research literature? In the case example of research with Latina women, for example, women stated their education was the most important identity identifier. For these new immigrant mothers, they aspired to be more educated in general (not related to asthma) as a way to care for their children, but this view has not been documented in prior research as important.

Researchers can advance social justice through emancipatory research that explicitly explores how participants describe their identity and health. Researchers can carve interpretative spaces using the I-ReH-DO Interview and reflect on their own normative assumptions about identity and health. This will help forecast future research needs because researchers will gain insight into how power relationships inform both identity and health.

\section{Summary}

In this era when socio-political ideologies of health are being noticed and questioned, emancipatory research that fosters identity empowerment is warranted. This article portrays three case examples that used the I-ReH-DO Interview to address health as rooted in socially constructed identities. The I-ReH-Do Interview intentionally elicits conversations about the manifestation of structural privilege and inequalities through identity, and its impact on health. This innovative research interview advances nursing science by offering a concrete method for eliciting and analyzing identity and health concerns. The I-ReH-DO Interview modernizes interviewing within a transformative social justice agenda to facilitate discovery and acknowledgement of power relations, socio-political agendas, and disparities related to identity. 


\section{Creating Emancipatory Dialogues}

\section{References}

1. Walker R. Emancipatory Nursing Praxis: A Theory of Social Justice. Advances in Nursing Science 2017;40(3)

2. Boutain D. The identity, research, and health dialogic interview: Its significance for social justice-oriented research. In: P. N. Kagan MCS, \& P. L. Chinn (Eds.), ed. Philosophies and practices of emancipatory nursing: Social justice as praxis. New York: Routledge, 2014:124-35.

3. Oxford English Dictionary 3rd Edition. Secondary Oxford English Dictionary 3rd Edition 2014.

4. M. W, editor. Social identity New York: Nova Science Publishers, 2011.

5. Boutain D. Social Justice as a Concept for Nursing In: DeChesnay MaA, B., ed. Caring for the Vulnerable. 4th ed: Jones and Bartlett Learning, 2016.

6. Hall JaC, K. . Marginalization: A Revisitation with Integration of Scholarship on Globalization, Intersectionality, Privilege, Microaggressions, and Implicit Biases. Advances in Nursing Science 2016;39(3):200-15

7. Keet CA, McCormack, M. C., Pollack, C. E., Peng, R. D., McGowan, E., \& Matsui, E. C. . Neighborhood poverty, urban residence, race/ethnicity, and asthma: Rethinking the inner-city asthma epidemic. Journal of Allergy and Clinical Immunology 2015;135(3):655-62

8. Shanawani $\mathrm{H}$. Health disparitis and difference in asthma: Concepts and controversies. Clinics in Chest Medicine 2006;27(1):17-28

9. Evans-Agnew R. Development and pilot testing of a bilingual environmental health assessment tool to promote asthma-friendly childcares. Progress in Community Health Partnerships: Research, Education, and Action 2018;12(1):35-44

10. Evans-Agnew R. Asthma management disparities: A photovoice investigation with African American youth. Journal of School Nursing 2016;32(2):99-111

11. Brickle $M$, and Evans-Agnew, R. Photovoice and youth empowerment in environmental justice research: A pilot study examining woodsmoke in a Pacific Northwest community Journal of Community Health Nursing 2017 34(2):89-101

12. Evans-Agnew R, Postma, J., and Sledd, L. Mi niño con asma: Hispanic/Latina mothers, environmental justice, and photovoice at the front lines of the asthma epidemic. Journal of Health Disparity Research and Practice 2016;9(1):Article 7

13. Evans-Agnew R. Asthma disparity photovoice: The discourses of Black adolescents and public health policy makers. Health Promotion Practice 2017;19(2):213-21

14. Monterio L, Musten, M., \& Compson, R. Traditional and contemporary mindfulness: Finding the middle path in the tangle of concerns. Mindfulness 2015;6(1):1-13

15. Redon J, Mourand, J. J., Schmieder, R. E., Volpe, M., \& Weiss, T. W. . Why in 2016 are patients with hypertension not $100 \%$ controlled? A call to action. . Journal of Hypertension 2016;34(8):1480-8

16. Kuller LH. Yet another study reports poor control of elevated blood pressure. American Journal of Hypertension 2014;27(6):773-74

17. National Center for Chronic Disease Prevention and Health Promotion DoHDaSP. High Blood Pressure. Secondary High Blood Pressure 2018.

18. Rosenthal T. The effect of migration on hypertension and other cardiovascular risk factors: $A$ review. Journal of the American Society for Hypertension 2014;8(3):171-91

19. Rosemberg M, Johnson-Lawrence, V., Rostant, O., and McCullagh, M. Significant associative factors for hypertension among new US immigrants: An exploration of the 2003 New Immigrant Survey (NIS) Data Journal of Community and Public Health Nursing 2016;2(118) 


\section{Creating Emancipatory Dialogues}

20. Gyamfi J, Butler, M., Williams, S. K., Agymeang, C., Gyamfi, L., Seixas, A.... \& Ogedegbe, G. . Blood pressure control and mortality in US and foreign born blacks in New York City. The Journal of Clinical Hypertension 2017;19(10):956-64

21. Bacon E, Riosemena, F., \& Rogers, R. G. . Does the Hispanic health advantages extend to better management of hypertension? The role of socioeconomic status, sociobehavioral factors, and health care access. Biodemography and Social Biology 2017;63(3):262-77

22. Sanon MaT, J. . Connecting gender, race, class, and immigration status to disease management Journal of Health Disparities Research and Practice 2014;7(5):13-31

23. Sanon MA, Springer, C., and McCullagh, M. Transnationalism and hypertension selfmanagement among Haitian immigrants. Journal of Transcultural Nursing 2014;27(2):147-56

24. Posner SF, Johnson, K., Parker, C., Atrash, H., \& Bierman, J. The national summit on preconception care: A summary of concepts and recommendations. Maternal Child Health Journal 2006;10:197-205

25. Johnson K, Posner, S. F., Biermann, J., Cordero, J. F., Atrash, H. K., Parker, C. S., Boulet, S., \& Curtis, M. G. . Recommendations to improve preconception health and health care - United States: A report of the CDC/ATSDR preconception care work group and the select panel on preconceptino care. Morbidity and Mortality Weekly Report (MMWR) 2006;55(RR-6):1-23

26. Canady RB, Tiedje, L. B., \& Lauber, C. Preconception care \& pregnancy planning: Voices of African American women. MCN: The American Journal of Maternal/Child Nursing 2008;33(2):90-97 